\title{
STUDI KASUS BLACKSPOT SPBU MAYOR BISMO KOTA KEDIRI
}

\author{
Ayu Wulan Rahmawati ${ }^{1}$, Sumantri Widya Praja ${ }^{2}$, Arini Dewi Lestari ${ }^{3}$ \\ 1), 2), 3)PTDI-STTD \\ Email: sumantri.praja@ptdisttd.ac.id
}

\begin{abstract}
The city of Kediri is part of the administrative area of East Java Province. It is bordered by Ngadirejo District, Ngadiluwih District, Gampengrejo District and Semen District. To make travel movements outside the city of Kediri, especially Nganjuk and Surabaya, all types offour-wheeled and two-wheeled vehicles, goods transport vehicles, passenger transport and private vehicles will pass on the Mayor Bismo road. This causes a high rate of accidents on the Major Bismo road section, besides that the traffic volume is quite high. With the high volume of traffic, the possibility of an accident rate on the road segment is also high. Seeing the reality on the ground, accidents are a problem that must get complex attention. Accidents can be caused by several factors such as drivers, vehicles, infrastructure (roads and equipment) and environmental conditions. Based on accident data that has been obtained from the Kediri City Police Resort and the results of a field survey, it is obtained data that the Major Bismo road has a high number of accidents compared to the others. By looking at the high number of accidents, several alternative solutions to problems related to improving traffic safety and countermeasures to reduce traffic accidents on the highway are given, especially on the Major Bismo road. Keywords: accidents, roads, factors causing accidents.
\end{abstract}

\begin{abstract}
ABSTRAK
Kota Kediri merupakan bagian dari wilayah administratif Provinsi Jawa Timur. Berbatasan dengan kecamatan Ngadirejo, Kecamatan Ngadiluwih, Kecamatan Gampengrejo dan Kecamatan Semen. Untuk melakukan pergerakan perjalanan menuju luar Kota Kediri khususnya Nganjuk dan Surabaya semua jenis kendaraan roda empat dan roda dua, kendaraan angkutan barang, angkutan penumpang dan kendaraan pribadi akan melintas pada ruas jalan Mayor Bismo. Hal tersebut menyebabkan tingginya tingkat kecelakaan pada ruas jalan Mayor Bismo, selain itu juga volume lalu lintas cukup tinggi. Dengan tingginya volume lalu lintas maka kemungkinan tingkat kecelakaan pada ruas jalan tersebut juga tinggi. Melihat kenyataan di lapangan, kecelakaan merupakan suatu masalah yang harus mendapatkan perhatian yang kompleks. Kejadian kecelakaan dapat disebabkan oleh beberapa faktor seperti faktor pengemudi, kendaraan, prasarana (jalan dan perlengkapannya) dan kondisi lingkungan. Berdasarkan data kecelakaan yang telah diperoleh dari Kepolisian Resort Kota Kediri dan hasil survei di lapangan maka diperoleh data bahwa ruas jalan Mayor Bismo memiliki jumlah kecelakaan yang cukup tinggi dibandingkan dengan yang lain. Dengan melihat jumlah kecelakaan yang tinggi maka diberikan beberapa alternatif pemecahan masalah yang berhubungan dengan peningkatan keselamatan lalu lintas dan upaya penanggulangan untuk mengurangi kecelakaan lalu lintas pada jalan raya terutama pada ruas jalan Mayor Bismo.
\end{abstract}

Kata kunci: kecelakaan, ruas jalan, faktor penyebab kecelakaan

\section{PENDAHULUAN}

Keselamatan lalu lintas merupakan pengetahuan dalam hal mengurangi terjadinya kecelakaan lalu lintas, keselamatan dalam berlalu lintas saat ini sangat memprihatinkan karena kurang seriusnya pemerintah dalam menangani masalah keselamatan lalu lintas di jalan. Hal ini dapat diketahui dari tingginya tingkat kecelakaan yang terjadi dalam beberapa tahun terakhir. Tingkat keselamatan lalu lintas di suatu wilayah dapat diketahui dari banyaknya kecelakaan lalu lintas yang terjadi setiap tahun di wilayah tersebut.

Tingginya tingkat kecelakaan yang terjadi tidak lepas dari perkembangan industri perakitan kendaraan bermotor di Indonesia yang cukup pesat dan kemampuan daya beli masyarakat untuk membeli kendaraan bermotor terutama sepeda motor, serta kemudahan untuk membeli sepeda motor yang diberikan oleh perusahaan seperti kredit dan lain sebagainya, sehingga dari statistik kecelakaan yang terjadi di jalan raya didominasi oleh sepeda motor. Tingginya peningkatan penggunaan kendaraan bermotor di jalan tidak dibarengi dengan penyediaan prasarana yang baik, bahkan banyak 
prasarana yang kurang mendapat perawatan seperti permukaan jalan yang rusak serta rambu yang terhalang oleh pepohonan menjadi salah satu penyebab terjadinya kecelakaan.

Keselamatan lalu lintas merupakan masalah yang kompleks. Di dalam pembahasannya keselamatan lalu lintas sangat erat hubungannya dengan kecelakaan di jalan, maka dalam pembahasannya haruslah dikaitkan dengan faktor-faktor lain seperti faktor manusia, faktor sarana, faktor prasarana dan faktor lingkungan. Menurut pengamatan masyarakat di Kota Kediri, dan data yang didapat dari Kepolisian Kota Kediri ruas jalan Mayor Bismo adalah ruas jalan rawan kecelakaan, karena pada ruas jalan Mayor Bismo ini berperan sebagai lalu lintas yang berfungsi sebagai jalan Arteri dengan status jalan Nasional. Kecepatan kendaraan pada Jalan Mayor Bismo juga cukup tinggi, dan banyak akses gang-gang kecil. Dengan keadaan jalan yang cukup ramai kecelakaan yang terjadi di Kota Kediri perlu dilakukan suatu kajian sebagai acuan di dalam menentukan upaya pencegahannya secara efektif dan efisien. Oleh karena itu peneliti berupaya untuk meneliti mengenai black spot SPBU Mayor Bismo Kota Kediri agar permasalahan kecelakaan ini dapat diselesaikan sehingga dapat meningkatkan keselamatan bagi pengguna jalan di ruas jalan arteri Mayor Bismo dengan melakukan tindakan- tindakan manajemen lalu lintas.

\section{KAJIAN LITERATUR Aspek Teoritis}

Black spot merupakan lokasi pada ruas jalan (berupa spot) di mana frekuensi kecelakaan atau jumlah kecelakaan lalu lintas dengan korban mati, atau kriteria kecelakaan lainnya, per tahun lebih besar daripada jumlah minimal yang diperkirakan. (Investigasi Daerah rawan Kecelakaan).

Tidak semua lokasi yang mengalami kecelakaan lalu lintas dipastikan akan diperbaiki dan disertakan ke dalam program penanganan daerah rawan kecelakaan. Dalam hal ini tergantung pada jumlah keuangan dan sumber daya lain yang tersedia serta kriteria yang digunakan untuk menentukan suatu daerah rawan kecelakaan. Untuk mengidentifikasi lokasi daerah rawan kecelakaan, terlebih dahulu memerlukan definisi "ukuran" lokasi tersebut dan "kriteria" untuk memperbaiki persoalan tersebut.

Berdasarkan Pedoman Lokasi Rawan Kecelakaan Lalu lintas (Pd T-09- 2004-B), lokasi rawan kecelakaan merupakan suatu lokasi di mana angka kecelakaan tinggi dengan kejadian kecelakaan berulang dalam suatu ruang dan rentang waktu yang relatif sama yang diakibatkan oleh suatu penyebab tertentu. Suatu lokasi dinyatakan sebagai lokasi rawan kecelakaan lalu lintas apabila:

a) Memiliki angka kecelakaan yang tinggi;

b) Lokasi kejadian kecelakaan relatif menumpuk;

c) Kecelakaan terjadi dalam ruang dan rentang waktu yang relatif sama; dan

d) Memiliki penyebab kecelakaan dengan faktor yang spesifik.

\section{Aspek Legalitas}

Dasar hukum yang dipakai untuk menyusun pedoman teknis ini adalah:

a) Undang-Undang No. 22 tahun 2009 tentang Lalu Lintas dan Angkutan Jalan dengan pasal:

1) Pasal 1

- Ayat 31

Keselamatan Lalu Lintas dan Angkutan Jalan adalah suatu keadaan terhindarnya setiap orang dari risiko kecelakaan selama berlalu lintas yang disebabkan oleh manusia, kendaraan, jalan dan/atau lingkungan.

- Ketertiban Lalu Lintas dan Angkutan Jalan adalah suatu keadaan berlalu lintas yang berlangsung secara teratur sesuai dengan hak dan kewajiban setiap pengguna jalan.

2) Pasal 109

Pengemudi kendaraan bermotor yang akan melewati kendaraan lain harus menggunakan lajur atau jalur jalan sebelah kanan dari kendaraan yang akan dilewati, mempunyai jarak pandang yang bebas, dan tersedia ruang yang cukup. 
b) PM 13 tahun 2014 tentang rambu-rambu

Dalam Keputusan Menteri ini menerangkan rambu-rambu yang berada di jalan yang tertera dalam pasal :

1) Pasal 3

Rambu Lalu Lintas berdasarkan jenisnya terdiri atas:

- rambu peringatan;

- rambu larangan;

- rambu perintah; dan

- rambu petunjuk.

2) Pasal 4

- Rambu Lalu Lintas sebagaimana dimaksud dalam Pasal 3 dapat berupa:

a. Rambu Lalu Lintas konvensional; atau

b. Rambu Lalu Lintas elektronik.

- Rambu Lalu Lintas konvensional sebagaimana dimaksud pada ayat (1) huruf a berupa rambu dengan bahan yang mampu memantulkan cahaya atau retro reflektif.

3) Rambu Lalu Lintas elektronik sebagaimana dimaksud pada ayat (1) huruf b berupa rambu yang informasinya dapat diatur secara elektronik.

c) PM 111 Tahun 2015 tentang Tata Cara Penetapan Batas Kecepatan

1) Pasal 2

- Penetapan batas kecepatan dimaksudkan untuk mencegah kejadian dan fatalitas kecelakaan serta mempertahankan mobilitas lalu lintas.

- Penetapan batas kecepatan bertujuan untuk kualitas hidup masyarakat.

- Pengaturan mengenai tata cara penetapan batas kecepatan sebagaimana diatur dalam peraturan ini merupakan norma, standar, prosedur dan kriteria dalam penetapan batas kecepatan.

2) Pasal 3

- Setiap jalan memiliki batas kecepatan paling tinggi yang ditetapkan secara nasional.

- Batas kecepatan paling tinggi sebagaimana dimaksud pada ayat 1 meliputi :

a. Batas kecepatan jalan bebas hambatan.

b. Batas kecepatan jalan antar kota.

c. Batas kecepatan jalan pada kawasan perkotaan, dan

d. Batas kecepatan jalan pada kawasan permukiman.

- Untuk jalan bebas hambatan sebagaimana dimaksud pada ayat (2) huruf a ditetapkan batas kecepatan paling rendah.

- Batas kecepatan sebagaimana dimaksud pada ayat (2) dan ayat (3) ditetapkan:

a. Paling rendah $60 \mathrm{KM}$ per jam dalam kondisi arus bebas dan paling tinggi 100 kilometer per jam untuk jalan bebas hambatan.

b. Paling tinggi $80 \mathrm{KM}$ per jam untuk jalan antar kota.

c. Paling tinggi $50 \mathrm{KM}$ per jam untuk kawasan perkotaan, dan

d. Paling tinggi $30 \mathrm{KM}$ per jam untuk kawasan permukiman.

- Batas kecepatan paling tinggi dan batas kecepatan paling rendah sebagaimana dimaksud pada ayat (4) harus dinyatakan dengan rambu lalu lintas.

\section{Proses Penetapan Batas Kecepatan di Jalan Arteri Primer}

Jika jalur cepat dan jalur lambat tidak dipisahkan median maka batas kecepatan paling tinggi ditentukan berdasarkan:

a) Tipe penggunaan lahan, dibagi menjadi 4 bagian :

1) Kawasan pusat kegiatan maka kecepatan paling tinggi 40 kilometer per jam.

2) Kawasan industri, dibagi menjadi :

- Pada saat jam kerja karyawan maka kecepatan paling tinggi 40 kilometer per jam. 
- Di luar jam kerja karyawan maka kecepatan paling tinggi 80 kilometer per jam untuk kendaraan bermotor roda empat atau lebih dan untuk sepeda motor 60 kilometer per jam.

3) Kawasan permukiman ditentukan kecepatan paling tinggi 40 kilometer per jam.

4) Kawasan sekolah, dibagi menjadi:

- Pada jam masuk atau pulang sekolah batas kecepatan paling tinggi untuk semua kendaraan adalah 30 kilometer per jam.

- Di luar jam masuk atau pulang sekolah batas kecepatan paling tinggi 80 kilometer

\section{METODE} per jam untuk kendaraan bermotor dan 60 kilometer per jam untuk sepeda motor.

Metode penelitian ini meliputi pengumpulan berbagai informasi berkaitan dengan data yang diperlukan untuk mengadakan analisis permasalahan pada daerah penelitian. Metode yang digunakan dalam pengumpulan data adalah data sekunder yang berasal dari instansi terkait dengan data primer yang dilakukan melalui survei. Metode pendekatan dalam mengumpulkan data antara lain adalah metode survei lapangan, metode instansional dan metode kepustakaan.

\section{PEMBAHASAN}

\section{Penentuan Lokasi Rawan Kecelakaan}

Lokasi daerah rawan kecelakaan ditentukan dengan cara pembobotan sesuai dengan tingkat fatalitas kecelakaan. Hasil pembobotan yang dilakukan pada data kecelakaan yaitu dari tahun 20122015 yang ada di Kota Kediri sehingga diketahui ruas jalan yang paling rawan yaitu Ruas Jalan Mayor Bismo. Dalam menganalisis permasalahan kecelakaan lalu lintas pada daerah rawan kecelakaan ini menggunakan analisa makro dan mikro.

\section{Analisa Makro}

Analisa makro mengidentifikasikan karakteristik-karakteristik yang sifatnya umum, yang dilakukan dengan tahapan sebagai berikut:

a) Analisa numerik sederhana terhadap waktu kejadian.

1) Tahun Kejadian

Adapun dari hasil kecelakaan periode tahun 2012-2015 untuk ruas jalan Mayor Bismo didapat tahun yang paling banyak terjadinya kecelakaan yaitu tahun 2013 sebanyak 26 kejadian.

Untuk lebih jelasnya dapat dilihat dalam tabel V.1 di bawah ini.

Tabel 1. Jumlah kecelakaan di ruas jalan Mayor Bismo Tahun 2012 - 2015

\begin{tabular}{|c|c|c|c|c|c|c|}
\hline \multirow{2}{*}{ NO } & \multirow{2}{*}{ TAHUN } & \multirow{2}{*}{\begin{tabular}{c}
\multirow{2}{*}{ KUMLAH } \\
KEJADIAN
\end{tabular}} & \multicolumn{3}{|c|}{ KORBAN } & \multirow{2}{*}{ PEMBOBOTAN } \\
\cline { 4 - 6 } & & 26 & MD & LB & LR & \\
\hline 1 & 2012 & 31 & 3 & 4 & 27 & 34 \\
\hline 2 & 2013 & 24 & 2 & 3 & 20 & 57 \\
\hline 3 & 2014 & 16 & 2 & 1 & 17 & 41 \\
\hline 4 & 2015 & & & & 32 \\
\hline
\end{tabular}

2) Bulan Kejadian

Analisis menurut bulan kejadian digunakan untuk mengetahui bulan mana yang memiliki jumlah kecelakaan paling tinggi. Hasil analisis pada bulan kejadian kecelakaan dapat dilihat pada tabel dan gambar V.2 di bawah ini:

Tabel 2. Data Kejadian kecelakaan berdasarkan Bulan Kejadian di ruas Jalan Mayor Bismo

\begin{tabular}{|c|c|c|}
\hline NO & BULAN & TOTAL \\
\hline 1 & Januari & 9 \\
\hline 2 & Februari & 5 \\
\hline
\end{tabular}




\begin{tabular}{|c|c|c|}
3 & Maret & 3 \\
\hline 4 & April & 6 \\
\hline 5 & Mei & 5 \\
\hline 6 & Juni & 10 \\
\hline 7 & Juli & 12 \\
\hline 8 & Agustus & 9 \\
\hline 9 & September & 7 \\
\hline 10 & Oktober & 8 \\
\hline 11 & Nopember & 9 \\
\hline 12 & Desember & 14 \\
\hline
\end{tabular}

3) Waktu Kejadian ( Jam )

Untuk mengetahui tingkat keparahan kecelakaan selama 24 jam dari tahun 2012 - 2015 di Kota Kediri dapat dilihat pada Tabel V.3 di bawah ini.

Tabel 3. Data Kejadian kecelakaan berdasarkan Jam Kejadian di ruas Jalan Mayor Bismo

\begin{tabular}{|c|c|c|c|c|c|c|c|c|c|}
\hline \multirow[b]{2}{*}{ TAHUN } & \multicolumn{8}{|c|}{ WAKTU KEJADIAN } & \multirow[b]{2}{*}{ JUMLAH } \\
\hline & $\begin{array}{c}00.00 \\
\text { s/d } \\
03.00\end{array}$ & $\begin{array}{c}03.00 \\
\text { s/d } \\
06.00\end{array}$ & $\begin{array}{c}06.00 \\
\text { s/d } \\
0900\end{array}$ & $\begin{array}{c}09.00 \\
\text { s/d } \\
12.00\end{array}$ & $\begin{array}{c}12.00 \\
\text { s/d } \\
15.00\end{array}$ & $\begin{array}{c}15.00 \\
\text { s/d } \\
18.00\end{array}$ & $\begin{array}{c}18.00 \\
\text { s/d } \\
21.00\end{array}$ & $\begin{array}{c}21.00 \mathrm{~s} / \mathrm{d} \\
24.00\end{array}$ & \\
\hline 2012 & 0 & 3 & 3 & 1 & 2 & 6 & 4 & 1 & 20 \\
\hline 2013 & 1 & 2 & 3 & 3 & 5 & 10 & 2 & 0 & 26 \\
\hline 2014 & 0 & 1 & 4 & 3 & 6 & 7 & 5 & 2 & 28 \\
\hline 2015 & 1 & 2 & 2 & 5 & 6 & 4 & 3 & 0 & 23 \\
\hline JUMLAH & 2 & 8 & 12 & 12 & 19 & 27 & 14 & 3 & 97 \\
\hline
\end{tabular}

4) Analisis berdasarkan usia yang terlibat

Dari hasil analisa kecelakaan menurut usia terlibat kecelakaan dapat diketahui bahwa usia yang paling sering terlibat kecelakaan adalah usia antara 16 - 30 Tahun berjumlah 29 orang. Korban kecelakaan sebagian besar dan berusia produktif di mana keberadaannya sangat dibutuhkan di kalangan masyarakat dan anggota keluarganya. Hal ini mungkin disebabkan karena pada saat usia tersebut orang-orang lebih sering bepergian untuk pergi bekerja.

Untuk lebih jelasnya dapat dilihat pada tabel V.4. di bawah ini.

Tabel 4. Data Jumlah Kecelakaan Berdasarkan Usia Korban Kecelakaan di ruas jalan Mayor Bismo

\begin{tabular}{|c|c|c|c|c|c|c|c|}
\hline \multirow{2}{*}{ NO } & \multirow{2}{*}{ TAHUN } & \multicolumn{7}{|c|}{ USIA KECELAKAAN } \\
\cline { 3 - 8 } & & $(\mathbf{0 - 9})$ & $(\mathbf{1 0 - 1 5})$ & $(\mathbf{1 6 - 3 0 )}$ & $\mathbf{( 3 1 - 4 0 )}$ & $\mathbf{( 4 1 - 5 0 )}$ & 51 KEATAS \\
\hline 1 & 2012 & 1 & 2 & 6 & 3 & 2 & 3 \\
\hline 2 & 2013 & 2 & 3 & 9 & 9 & 5 & 4 \\
\hline 3 & 2014 & 1 & 3 & 7 & 8 & 6 & 3 \\
\hline 4 & 2015 & 1 & 1 & 7 & 3 & 4 & 4 \\
\hline \multicolumn{2}{|l}{ JUMLAH } & 5 & 9 & 29 & 23 & 17 & 14 \\
\hline
\end{tabular}

5) Analisa kecelakaan berdasarkan jenis kendaraan yang terlibat

Dilihat dari jenis kendaraan yang terlibat dalam jangka waktu antara tahun $2012-2015$, yang sering terjadi kecelakaan di ruas jalan Mayor Bismo adalah kendaraan sepeda motor

Tabel 5. Jenis Kendaraan yang terlibat kecelakaan di ruas jalan Mayor Bismo

\begin{tabular}{|c|c|c|c|c|c|c|}
\hline \multirow{2}{*}{ NO } & \multirow{2}{*}{ TAHUN } & \multicolumn{5}{|c|}{ JENIS KENDARAAN YANG TERLIBAT } \\
\cline { 3 - 7 } & $\begin{array}{c}\text { JUMLAH } \\
\text { KEJADIAN }\end{array}$ & $\begin{array}{c}\text { SEPEDA } \\
\text { MOTOR }\end{array}$ & $\begin{array}{c}\text { MOBIL } \\
\text { PENUMPANG }\end{array}$ & $\begin{array}{c}\text { MOBIL } \\
\text { BARANG }\end{array}$ & $\begin{array}{c}\text { KENDARAAN } \\
\text { TIDAK } \\
\text { BERMOTOR }\end{array}$ \\
\hline 1 & 2012 & 26 & 25 & 4 & 2 & 1 \\
\hline 2 & 2013 & 31 & 31 & 7 & 5 & 0 \\
\hline 3 & 2014 & 24 & 26 & 5 & 4 & 0 \\
\hline
\end{tabular}




\begin{tabular}{|c|c|c|c|c|c|}
4 & 16 & 19 & 5 & 2 & 0 \\
\hline JUMLAH & 97 & 101 & 21 & 13 & 1 \\
\hline
\end{tabular}

6) Tipe tabrakan berdasarkan fatalitas korban

Berdasarkan jenis kecelakaan yang paling tinggi pada ruas jalan Mayor Bismo yaitu jenis kecelakaan depan-belakang. Berikut adalah tipe tabrakan berdasarkan fatalitas korban diruas jalan Mayor Bismo.

Tabel 6. Tipe tabrakan berdasarkan fatalitas korban di ruas jalan Mayor Bismo

\begin{tabular}{|c|c|c|c|c|c|c|}
\hline \multirow{2}{*}{ NO } & \multirow{2}{*}{ TIPE TABRAKAN } & \multirow{2}{*}{$\begin{array}{c}\text { JUMLAH } \\
\text { KEJADIAN }\end{array}$} & \multicolumn{2}{|c|}{ FATALITAS KORBAN } & \multicolumn{2}{c|}{$\begin{array}{c}\text { JUMLAH } \\
\text { BOBOT }\end{array}$} \\
\cline { 4 - 6 } & & MD (6) & LB (3) & LR (1) & 7 & 31 \\
\hline 1 & Tunggal & 14 & 2 & 4 & 4 & 43 \\
\hline 3 & Depan - Depan & 24 & 3 & 4 & 13 & 52 \\
\hline 4 & Depan - Belakang & 41 & 4 & 4 & 14 & 38 \\
\hline
\end{tabular}

7) Jenis kendaraan yang terlibat berdasarkan tipe tabrakan

Berdasarkan tipe tabrakan kendaraan yang paling sering terlibat kecelakaan pada ruas jalan Mayor Bismo adalah sepeda motor dengan tipe tabrakan depan-belakang. Karena populasi pengguna sepeda motor yang paling tinggi yang melintasi ruas jalan ini serta ditambahkan kondisi jalan yang kurang baik sehingga sangat sering terjadi kecelakaan dengan tipe tabrakan depan-belakang. Berikut adalah jenis kendaraan yang terlibat berdasarkan tipe tabrakan di ruas jalan Mayor Bismo.

Tabel 7. Kendaraan yang terlibat berdasarkan tipe tabrakan di ruas jalan Mayor Bismo

\begin{tabular}{|c|c|c|c|c|c|}
\hline \multirow{2}{*}{ NO } & Kendaraan Yang Terlibat & \multicolumn{4}{c|}{ Tipe Tabrakan } \\
\cline { 3 - 5 } & Sepeda Motor & D-D & D-B & D-S & Tunggal \\
\hline 1 & MPU & - & - & - & 6 \\
\hline 2 & Mobil Penumpang Pribadi & - & - & - & - \\
\hline 3 & Angkutan Barang & - & - & - & 3 \\
\hline 4 & Sepeda Motor-Sepeda Motor & 8 & - & - & - \\
\hline 5 & Sepeda Motor-Mobil Penumpang Pribadi & 4 & 6 & 9 & - \\
\hline 6 & Sepeda Motor-Mpu & - & 2 & - & \\
\hline 7 & Sepeda Motor-Angkutan Barang & 9 & 7 & 3 & - \\
\hline 8 & Mobil Penumpang Pribadi-Mobil Penumpang & - & 2 & - & - \\
\hline 9 & Pribadi & 7 & 4 & 4 & \\
\hline 10 & Mobil Penumpang Pribadi-Angkutan Barang & 78 & - \\
\hline & Total & 28 & 39 & 21 & 9 \\
\hline
\end{tabular}

\section{Penanganan dan rekomendasi}

Dari berbagai macam kecelakaan yang terjadi, saya memberikan rekomendasi atau usulan terhadap pemerintah Kota Kediri untuk ruas jalan Mayor Bismo agar nantinya ruas jalan tersebut tidak menelan banyak korban. Di atas telah dijelaskan bahwa kecelakaan terjadi oleh beberapa faktor salah satunya adalah kurangnya rambu-rambu lalu lintas. Oleh karena itu saya mempunyai rekomendasi seperti di bawah ini :

a) Diberi pemisah lajur seperti median

b) Diberi pita penggaduh

c) Diberi rambu batas kecepatan $40 \mathrm{Km} / \mathrm{jam}$

d) Diberi rambu rambu lalu lintas

e) Diberi bill board tentang kecelakaan

f) Diberi pos pengamanan 


\section{KESIMPULAN}

Dari hasil analisis yang dilakukan dan terkait dengan tujuan dari penelitian maka diperoleh kesimpulan sebagai bahwa secara makro di dapat tahun, bulan dan jam kejadian kecelakaan yang ada pada ruas jalan Mayor Bismo dengan jumlah kecelakaan tertinggi pada tahun 2013 dengan jumlah kecelakaan terbanyak ada pada bulan Desember dan waktu acara keagamaan antara jam 15.00-18.00 WIB. Kemudian berdasarkan tipe tabrakan kendaraan yang terlibat yang paling banyak terjadi kecelakaan adalah sepeda motor dengan tipe tabrakan depan-belakang. Terakhir prasarana jalan yang kurang baik seperti jalan berlubang dan jalan bergelombang sangat berpotensi menimbulkan kecelakaan.

\section{REFERENSI}

1. Republik Indonesia. 2012-2015. Satlantas Polres Kota Kediri.

2. Republik Indonesia. 2014. Kediri dalam Angka 2014. Pemda Kota Kediri.

3. Republik Indonesia. 2014. PM 13 Tahun 2014 tentang Marka Jalan.

4. Republik Indonesia. 2014. PM 13 Tahun 2014 tentang Rambu-rambu.

5. Republik Indonesia. 2015. PM 111 Tahun 2015 tentang Cara Penetapan Batas Kecepatan..

6. Republik Indonesia. 2016. Pola Umum Lalu Lintas Dan Angkutan Jalan Kota Kediri dan identifikasi permasalahanya. PKL Taruna/i Angkatan XXXV.

7. Republik Indonesia.1988. Badan Diklat Perhubungan Pusat Pendidikan dan Latihan Perhubungan Darat.

8. Republik Indonesia. 2009. UU LLAJ No. 22 Tahun 2009 tentang Lalu Lintas dan Angkutan Jalan. 